\title{
Does Eye Camp Contribute to the Fight against Blindness? Experience of the Central Region in Togo
}

\section{Kassoula Batomaguela Nonon Saa1, Nidain Maneh2², Messan Kokou Amedome ${ }^{3}$, Kokou Vonor ${ }^{2}$, Kossi Dzidzinyo ${ }^{2}$, Koffi Didier Ayena ${ }^{2}$, Komi Patrice Balo ${ }^{2}$}

${ }^{1}$ Eye Department of Sokode, Faculty of Health Sciences, University of Lome, Lome, Togo

${ }^{2}$ Eye Department of Lome, Faculty of Health Sciences, University of Lome, Lome, Togo

${ }^{3}$ Eye Department of Kara, Faculty of Health Sciences, University of Lome, Lome, Togo

Email: *manehnid@hotmail.fr

How to cite this paper: Nonon Saa, K.B., Maneh, N., Amedome, M.K., Vonor, K., Dzidzinyo, K., Ayena, K.D. and Balo, K.P. (2017) Does Eye Camp Contribute to the Fight against Blindness? Experience of the Central Region in Togo. Open Journal of Ophthalmology, 7, 196-203.

https://doi.org/10.4236/ojoph.2017.73027

Received: June 24, 2017

Accepted: August 1, 2017

Published: August 4, 2017

Copyright $\odot 2017$ by authors and Scientific Research Publishing Inc. This work is licensed under the Creative Commons Attribution International License (CC BY 4.0).

http://creativecommons.org/licenses/by/4.0/

(c) (i) Open Access

\begin{abstract}
Aim: To evaluate results of cataract surgery in Eye Camp in rural areas. Patients and Method: This study set about the retrospective analysis of cases and operating reports of patients over the age of 10, operated for cataract in Eye Camp and fixed strategy from January, 2010 to December, 2012. Postoperative data were specified and compared. Results: Out of a total of 1145 patients operated, 577 (50.40\%) were men compared with 568 (49.60\%) women. The general mean age was 62 years, similar in Eye Camp and in fixed strategy. Sixty percent of patients were operated in Eye Camp. After 4 weeks of follow-up, $77 \%$ of patients were met again, and $83 \%$ among them showed good results (corrected visual acuity $=3 / 10$ ). This rate of good results was 80.43\% in Eye Camp against $87.7 \%$ in fixed strategy. We noted $18.25 \%$ of complications among which $11.25 \%$ were in Eye Camp. The functional outcomes of both strategies get closer to WHO standards. Conclusion: Eye Camp in the Central Region of Togo is an interesting alternative that contributes to the fight against blindness, even if postoperative follow-up is still to be improved.
\end{abstract}

\section{Keywords}

Cataract, Surgery, Eye Camp, Functional Outcomes

\section{Introduction}

Developing countries generally, and especially those in Sub-Saharan Africa, suffer both from a shortage of eye care specialized staff and from an inappropriate distribution of such staff [1] [2] [3]. Specialized personnel concentrate in a few 
existing eye care centers in some large urban centers, leaving rural areas where pathologies are concentrated [1] [4] [5].

This explains partially the low rates of cataract surgery, with functional outcomes not meeting expectations [2] [6] [7].

The "eye camp" strategy which consists of performing cataract surgery in camps gathering a large mass of rural populations, put in place to address this shortage, gives disappointing results [5] [7] [8].

The current challenge is not only assuring a sufficient surgical coverage but also about obtaining good results [5] [9].

The Eye Camp alternative is implemented in eye care units in semi-rural areas held by Senior Technicians of Ophthalmology (STO) in the central region of Togo for a few years. The current study has for objective to evaluate the functional outcomes and the follow-up of patients operated for cataract in "eye camp" (EC) and in fixed strategy (FS) according to World Health Organization (WHO) standards.

\section{Patients and Method}

The study was conducted in the Central Region of Togo where a project of fight against blindness is implemented by the Ministry of Health supported by Swiss Red Cross in a partnership framework. The Regional Hospital is the reference center of the project area, which covers a total of 194 villages for a population estimated at approximately 350,000 inhabitants.

This study set about the retrospective analysis of all cases and operating reports of patients who underwent a cataract surgery between January $1^{\text {st }}, 2010$ and December $31^{\text {st }}, 2012$. Those operated and followed in the regional reference center were considered as FS patients, whereas those operated and followed in the 4 health districts of the central region were considered as EC patients. The patients under the age of 10 , and those operated before or after the period of study were excluded. A cataract was operable when the visual acuity (VA) was not more than counting fingers at 2 meters.

\subsection{The Eye Camp (EC)}

The Eye Camp of cataract surgery had taken place in several stages.

The four health districts where it took place had a consultation room equipped with basic ophthalmological equipment. Two STOs consulted in fixed strategy but also carried out EC twice a week using off-road bikes in villages far from the center to recruit patients to operate. Patients with operable cataracts were invited to the district for the effectiveness of the operation only after their oral consent. On the eve of the operation, the team of the concerned district was in charge of getting patients ready, preparing their files, filling in elaborated forms attached to these files for the cataract surgery, and the consultation room which had to serve as operating room on the following day. All patients had to wash hands and face with soap under the supervision of the STO.

The surgical team of the regional reference center, consisting of an ophthal- 
mologist and 2 STOs, moved with all equipment for surgery including an autoclave using gas and a generator. It should be noted that the only regional ophthalmologist re-examined all patients by slit-lamp before the surgery. After the operation, the mobile surgical team returned and assigned postoperative followup of the patients to the resident STO.

\subsection{The Surgical Technique}

The conventional Extracapsular Extraction (ECE) with posterior chamber lens implantation under local anesthesia was the only technique practiced in both strategies. Standard rigid intraocular lens (IOL) of Aurolab PMMA (Polymethyl methacrylate) were used, with a power from 20 to 22 diopters depending on the availability for the posterior chamber and 19 diopters for the anterior chamber.

\subsection{Biosafety}

Biosafety measures according to the standards applied by the project partner in all the countries where it intervenes, have been systematically applied at all levels of surgery in the pre- as well as post-operative stages (isolation of patient, isolation of the operating room personnel, isolation of the operating room, skin disinfection with $10 \%$ povidone-iodine, washing of the conjunctival sac of the eye to operate with povidone-iodine diluted with saline, systematic autoclaving of resterilizable equipment, decontamination of instruments before sterilization). All stakeholders of the project were trained on these biosafety standards before their implementation and are regularly supervised.

\subsection{Follow-Up of the Patients Operated}

All the STOs in the project area were trained on a standardized follow-up protocol of people operated for cataract as well as on how to handle complications. Patients were informed about the warning signs that required urgent consultation: intense abnormal pain of the operated eye, with a decrease in vision or not. It was recommended to refer complicated cases to the ophthalmologist. A system of research of patients lost to follow-up was established through the collaboration between the STO, the community nurses and community health workers (CHW).

The study variables were age, sex, preoperative visual acuity (VA), postoperative uncorrected visual acuity (UVA), postoperative corrected visual acuity (CVA) obtained by pinhole test. The postoperative follow-up on the first day (D1) and the following weeks from the first week (W1) to the eleventh week (W11) with a systematic slit-lamp examination of all ocular structures, search anomalies or complications. The VAs were compared to WHO guidelines and recommendations [10] (Table 1).

\section{Results}

\subsection{Epidemiological Aspects}

A total of 1145 cases of patients operated for cataract were analyzed.

Five hundred and sixty-eight (568) were female (49.6\%), compared with five 
Table 1. WHO guidelines and recommendations concerning the postoperative result of cataract surgery with intraocular implant [10].

\begin{tabular}{ccc}
\hline Results & Postoperative uncorrected VA & Postoperative corrected VA \\
\hline Good $(10 / 10-3 / 10)$ & $80 \%$ & $+90 \%$ \\
Average $(1 / 10-3 / 10)$ & $15 \%$ & $<5 \%$ \\
$\operatorname{Bad}(<1 / 10)$ & $<5 \%$ & $<5 \%$ \\
\hline
\end{tabular}

VA: Visual acuity; Data collected on survey forms were entered and analyzed in the Epi Info software version 6.4 .

Table 2. Distribution of patients operated for cataract by age (years) group by sex and strategy.

\begin{tabular}{cccccc}
\hline & \multicolumn{2}{c}{ Eye camp } & \multicolumn{2}{c}{ Fixed strategy } & Rate \\
\cline { 2 - 6 } & F & M & F & M & n(\%) \\
\hline$[10-19]$ & 1 & 1 & 0 & 1 & $3(0.26)$ \\
{$[20-29]$} & 4 & 3 & 2 & 3 & $12(1.05)$ \\
{$[30-39]$} & 6 & 12 & 10 & 16 & $44(3.84)$ \\
{$[40-49]$} & 28 & 35 & 11 & 18 & $92(8.03)$ \\
{$[50-59]$} & 66 & 65 & 47 & 43 & $221(19.30)$ \\
{$[60-69]$} & 122 & 107 & 77 & 66 & $372(32.50)$ \\
{$[70-79]$} & 91 & 113 & 76 & 64 & $344(30.04)$ \\
$\geq 80$ & 7 & 15 & 20 & 15 & $57(4.98)$ \\
Total & 325 & 351 & 243 & 226 & $1145(100 \%)$ \\
\hline
\end{tabular}

$\mathrm{F}=$ Female; $\mathrm{M}=$ Male; $\mathrm{n}=$ number.

hundred and seventy-seven (577) male (50.4\%). In Eye Camp, out of a total of 676 patients, $52 \%$ were men against $48 \%$ women, while in FS out of 469 patients operated there were $52 \%$ women against $48 \%$ men (Table 2 ).

The general mean age was 62.16 years \pm 12.07 . In EC the mean age was 62.01 \pm 11.57 years, and in FS it was $62.31 \pm 12.7$. Sixty seven percent $(67 \%)$ of patients were over the age of 60 with extremes of 12 and 83, and five percent (5\%) were under the age of 30. This age distribution was as well respected in EC as in FS. Fifty nine percent (59\%) of patients were operated in EC against $41 \%$ in FS.

\subsection{Functional Outcomes}

On postoperative D1, we noted in EC $47.63 \%$ of good results and $47.78 \%$ of average results after correction, i.e. $95.42 \%$ of acceptable results against $4.58 \%$ of bad results. In FS, we noted $63.32 \%$ of good results and $29.42 \%$ of average results, i.e. $92.75 \%$ of acceptable results against $7.24 \%$ of bad results still after correction.

Globally, 882 patients were seen again between W4 and W11, i.e. 77\%. Among them 557 patients out of the 676 operated in EC were seen again, i.e. 82.39\%; while in FS, out of the 469 operated, 325 were seen again, i.e. $69.29 \%$.

Generally, the rates of $83 \%, 16 \%$, and $1 \%$ respectively good, average, and bad 
results after correction were found. In EC, these rates were respectively $80.43 \%$, $18.50 \%$, and $1.07 \%$ for the good, average, and bad results; while in FS they were $87.70 \%, 11.70 \%$, and $0.60 \%$ respectively for the good, average, and bad results (Table 3).

\subsection{Complications}

A total of 209 cases of complications were found over the 1,145 patients operated. In EC, this rate was $11.35 \%$ while it was $6.88 \%$ in FS. The endophthalmitis found in EC represented a rate of $0.087 \%$ ( 1 case out of 1145); the rupture of the posterior capsule with tissue prolapse or not represented $4.98 \%$ of the cases (57 over 1145) (Table 4).

\section{Discussions}

The patients operated benefited neither from the biometrics nor from the

Table 3. Functional outcomes of patients operated for cataract between postoperative W4-W11 in Eye Camp and in fixed strategy.

\begin{tabular}{|c|c|c|c|c|c|c|c|}
\hline \multirow{2}{*}{ Sex } & \multicolumn{3}{|c|}{ UVA } & \multirow{2}{*}{ Total } & \multicolumn{3}{|c|}{ CVA } \\
\hline & Good & Average & $\mathrm{Bad}$ & & Good & Average & $\mathrm{Bad}$ \\
\hline \multicolumn{8}{|c|}{ Eye Camp } \\
\hline M n (\%) & $145(49.15)$ & $143(48.47)$ & $7(2.37)$ & 295 & $237(80.34)$ & 55 (18.64) & $3(1.01)$ \\
\hline F n (\%) & $144(54.96)$ & $113(43.13)$ & $5(1.9)$ & 262 & $211(80.53)$ & $48(18.32)$ & $3(1.15)$ \\
\hline Total & $289(51.88)$ & $256(45.96)$ & $12(2.15)$ & 557 & $448(80.43)$ & $103(18.50)$ & $6(1.07)$ \\
\hline \multicolumn{8}{|c|}{ Fixed strategy } \\
\hline $\mathrm{Mn}(\%)$ & $90(58.06)$ & $62(40)$ & $3(1.93)$ & 155 & $140(90.32)$ & $15(9.68)$ & $0(0)$ \\
\hline F n (\%) & $100(58.82)$ & $68(40)$ & $2(1.17)$ & 170 & $145(85.30)$ & $23(13.53)$ & $2(1.17)$ \\
\hline Total & $190(58.46)$ & $130(40)$ & $5(1.54)$ & 325 & $285(87.70)$ & $38(11.70)$ & $2(0.60)$ \\
\hline
\end{tabular}

Table 4. Distribution of complications of patients operated for cataract in fixed strategy and in Eye Camp and by sex.

\begin{tabular}{ccccccc}
\hline & \multicolumn{2}{l}{ Eye camp } & Fixed strategy & Total \\
\cline { 2 - 7 } & M & F & M & F & n(\%) \\
\hline Endophthalmitis & 1 & 0 & 0 & 0 & $1(0.48)$ \\
Rupture of the posterior capsule with tissue prolapse or not & 20 & 22 & 10 & 5 & $57(27.27)$ \\
Hyphema & 0 & 0 & 1 & 1 & $2(0.95)$ \\
Remnants of crystalline materials & 6 & 9 & 3 & 7 & $25(11.96)$ \\
Hypertonia & 0 & 0 & 3 & 0 & $3(1.43)$ \\
Hernia of the iris & 2 & 2 & 0 & 0 & $4(1.91)$ \\
Corneal edema & 35 & 33 & 14 & 35 & $117(56)$ \\
Total & $\mathbf{6 4}$ & $\mathbf{6 6}$ & $\mathbf{3 1}$ & $\mathbf{4 8}$ & $\mathbf{2 0 9}(\mathbf{1 0 0})$ \\
\hline
\end{tabular}

$\mathrm{M}=$ Male; $\mathrm{F}=$ Female; $\mathrm{n}=$ number. 
preoperative check-up. Thus general co-morbidities such as high blood pressure and diabetes that have certain ocular implications were not excluded. Similarly, traumatic cataracts and those occurring in patients who are 10 to 20 years old were not excluded from our sample. All these findings constitute indisputable limits for the study which we believe do not alter the essential results. On the contrary, taking them into account could improve the quality.

The global sex ratio, in EC and in FS respectively 1.01, 1.08 and 0.99 in favor of men is close to 1 . Sixty-seven percent (67\%) of patients were over 60 years old and in both strategies the mean age was 62 years. These are probably mostly age-related cataracts and the two samples of population could have some homogeneity which would allow a fair comparison. Nirmalan et al. [4] in India had found a mean age similar to ours over 5411 patients. Gogate et al. [9] had found a mean age higher than ours 64.32 years over 383 patients operated in India in 2003, with a female predominance (54.05\%), as well as Guirou et al. (65 years) [6]. These disparities could be explained by the disparity of the samples. Fifty-nine percent of our cases were operated in Eye Camp. Limburg et al. [7] on a retrospective analysis of 4168 cases found $57 \%$ of cases operated in EC in India. In Nirmalan et al. [4], 76\% of the study population was rural. This makes us think that the rural environment would be more demanding in cataract surgery than the urban environment as other authors have found [1] [7], thus justifying the interest of EC of cataract surgery in rural areas.

On the first postoperative day, out of 1145 patients, the $\mathrm{VA} \geq 3 / 10$ increased from $24.54 \%$ with correction to $54.61 \%$ after correction. Similarly, the VA $<1 / 10$ decreased from $13.36 \%$ to $5.67 \%$ after correction, a result very close to WHO recommendations. This allows us to say that the residual ametropias represent a major cause of the bad results as most authors have found [2] [3] [5] [6]. To remedy this, a reconversion in technique reducing the residual ametropias is necessary for the surgeons, as well as the systematic calculation of the power of lens. Globally, between one and three months of follow-up, corrected VA have got closer to WHO standards concerning the good and average results (83\% and $16 \%$ respectively), while the bad results respected these standards (1\%). The slight superiority of the FS over the EC in terms of good results $(87.70 \%$ in fixed strategy versus $80.43 \%$ in Eye Camp) could be explained by the permanent presence of the ophthalmologist in fixed strategy that raises the level of the technical facilities in the follow-up. Anjum et al. [5] found 5.5\% of good results and $41.3 \%$ of bad results out of 218 patients operated in Pakistan. Guirou et al. [6] in Mali, found after best correction $63 \%, 22.9 \%$, and $14.1 \%$ respectively good, average, and bad results out of 2012 patients operated. If our results are superior to the results of these authors quoted above, they are similar to those of Yorston et al. [11] in Kenya who found $82.9 \%$ good results after correction out of 1800 patients operated. It should be noted that biometrics were made in their studies, and complicated and traumatic cataracts were excluded. But our results are below those of the Western countries [12].

What makes the difference between EC and FS is undoubtedly the quality of 
the follow-up. A good follow-up involves rapid detection of complications but also the number of patients followed, which is often low in developing countries, especially in the case of surgery in EC. In our case the percentage of patients found in EC was higher than that found in FS due to the implementation of a strategy to find the lost to follow-up through effective collaboration between the STO, the nurses and CHW of the distant localities.

Endophthalmitis which is a dramatic complication frequently leading to blindness was $0.087 \%$. Zaidi et al. [13] in England found a higher rate than ours $(0.1 \%)$ in an audit of 1000 cases operated through phacoemulsification. In this case, we are very far from the Swedish studies which are at revolutionary rates: Lundström et al. [14] found 109 cases out of 225,471 (0.048\%) and Friling et al. [15] found 135 cases out of 464,996 operations (0.029\%). Note that in Swedish studies there is a prophylactic use of cefuroxime intracamerally. The universal practice of this prophylaxis in developing countries becomes an imperative. The rate of complications (18.24\%) was globally lower than in Roth et al. [16] (31\% with the Kansas technique) and Gogate et al. [9] (24.54\%). Our rate is higher than that of Zaidi et al. [13] which is around 1\%. The complications in EC (11.35\%) being higher than those found in FS (6.88\%) could be explained by the quality of the follow-up where the technical facilities are better in FS.

\section{Conclusion}

The Eye Camp, like what is practiced in the central region of Togo, is an interesting alternative that helps to combat blindness. Its interest lies in the fact that it serves the rural populations who are the most vulnerable but also the most neglected, thus reducing blindness and its socio-economic consequences. Even if the results of this study are not exactly in line with WHO recommendations, they are much closer to them and thus help to address the dual challenge of underdeveloped countries in the fight against blindness: improve the quantity and quality of cataract surgery.

\section{Conflict of Interest}

The authors declare no conflict of interest.

\section{Ethical Approval}

Approval for the study was obtained from the national medical ethic committee.

\section{References}

[1] Thylefors, B. (2010) Soins Oculaires Primaires: Toujours un défi. Revue de Santé Oculaire Communautaire, 7, 1-3.

[2] Tabin, G., Chen, M. and Espandar, L. (2008) Cataract Surgery for the Developing World. Current Opinion in Ophthalmology, 19, 55-59. https://doi.org/10.1097/ICU.0b013e3282f154bd

[3] Bourne, R., Dineen, B., Jadoon, Z., et al. (2007) Outcomes of Cataract Surgery in Pakistan: Results from the Pakistan National Blindness and Visual Impairment Survey. British Journal of Ophthalmology, 91, 420-426. 
https://doi.org/10.1136/bjo.2006.106724

[4] Nirmalan, P.K., Thulasiraj, R.D., Maneksha, V., et al. (2002) A Population Based Eye Survey of Older Adults in Tirunelveli District of South India: Blindness, Cataract Surgery, and Visual Outcomes. British Journal of Ophthalmology, 86, 505-512. https://doi.org/10.1136/bjo.86.5.505

[5] Anjum, K.M., Qureshi, M.B., Khan, M.A., et al. (2006) Cataract Blindness and Visual Outcome of Cataract Surgery in a Tribal Area in Pakistan. British Journal of Ophthalmology, 90, 135-138. https://doi.org/10.1136/bjo.2005.078527

[6] Guirou, N., Napo, A., Dougnon, A., et al. (2013) Visual Outcome of Cataract Surgery in Adults. Journal Français d Ophtalmologie, 36, 19-22.

[7] Limburgn, H., Foster, A., Vaidyanathan, K. and Murthy, G.V. (1999) Monitoring Visual Outcome of Cataract Surgery in India. Bulletin of the World Health Organization, 77, 455-460.

[8] Bourne, R.R., Dineen, B.P., Ali, S.M., Huq, D.M. and Johnson, G.J. (2003) Outcomes of Cataract Surgery in Bangladesh: Results from a Population Based Nationwide Survey. British Journal of Ophthalmology, 87, 813-819.

https://doi.org/10.1136/bjo.87.7.813

[9] Gogate, P.M., Deshpande, M., Wormald, R.P., Deshpande, R. and Kulkarni, S.R. (2003) Extracapsular Cataract Surgery Compared with Manual Small Incision Cataract Surgery in Community Eye Care Setting in Western India: A Randomized Controlled Trial. British Journal of Ophthalmology, 87, 667-672. https://doi.org/10.1136/bjo.87.6.667

[10] Hennig, A. (2005) Chirurgie de la cataracte sans suture et sans phacoémulsification: Une solution pour réduire la cécité par cataracte dans le monde? Revue de Santé Oculaire Communautaire, 2, 4-5.

[11] Yorston, D., Gichuhi, S., Wood, M. and Foster, A. (2002) Does Prospective Monitoring Improve Cataract Surgery Outcomes in Africa? British Journal of Ophthalmology, 86, 543-547. https://doi.org/10.1136/bjo.86.5.543

[12] Norregaard, J.C., Berntt-Petersen, P., Alonso, J., Andersen, T.F. and Anderson, G.F. (2003) Visual Functional Outcomes of Cataract Surgery in the United States, Canada, Denmark and Spain: Report of the International Cataract Surgery Outcomes Study. Journal of Cataract \& Refractive Surgery, 29, 2135-2142.

[13] Zaidi, F.H., Corbett, M.C., Burton, B.J., Bloom, P.A. and Philip, A.B. (2007) Raising the Benchmark for the 21st Century-The 1000 Cataract Operations Audit and Survey: Outcomes, Consultant-Supervised Training and Sourcing NHS Choice. British Journal of Ophthalmology, 91, 731-736.

https://doi.org/10.1136/bjo.2006.104216

[14] Lundström, M., Wejde, G., Stenevi, U., Thorburn, W. and Montan, P. (2007) Endophthalmitis after Cataract Surgery: A Nationwide Prospective Study Evaluating Incidence in Relation to Incision Type and Location. Ophthalmology, 114, 866-870.

[15] Friling, E., Lundström, M., Stenevi, U. and Montan, P. (2013) Six-Year Incidence of Endophthalmitis after Cataract Surgery: Swedish National Study. Journal of Cataract \& Refractive Surgery, 39, 15-21.

[16] Roth, E., Ndoye, R.P.A., Wade, A., et al. (2000) Contribution of the Kansas Technique for Reducing Complications of Mature Cataract Surgery. Journal Français d Ophtalmologie, 23, 688-693. 
Submit or recommend next manuscript to SCIRP and we will provide best service for you:

Accepting pre-submission inquiries through Email, Facebook, LinkedIn, Twitter, etc. A wide selection of journals (inclusive of 9 subjects, more than 200 journals)

Providing 24-hour high-quality service

User-friendly online submission system

Fair and swift peer-review system

Efficient typesetting and proofreading procedure

Display of the result of downloads and visits, as well as the number of cited articles Maximum dissemination of your research work

Submit your manuscript at: http://papersubmission.scirp.org/

Or contact ojoph@scirp.org 